\title{
Vitamin E and Vitamin E Acetate Absorption from Self-assembly Systems under Pancreas Insufficiency Conditions
}

\author{
Kornél Nagya , Beatriz Lobob, Marie-Claude Courtet-Compondua, Sophie Braga-Lagachea, \\ Laura Ramos $^{b}$, Valentí Puig-Divic ${ }^{c}$ Fernando Azpiroz ${ }^{\text {bd }}$, Juan Ramón Malagelada ${ }^{\text {bd }}$, \\ Maurice Beaumont ${ }^{a}$, Julie Moulin ${ }^{a}$, Simone Acquistapace ${ }^{a}$, Laurent Sagalowicz ${ }^{a}$, \\ Martin Kussmann ${ }^{\star}$ efg, Javier Santos ${ }^{\text {bd }}$, Birgit Holst ${ }^{\mathrm{a}}$, and Gary Williamson ${ }^{\mathrm{h}}$
}

\begin{abstract}
We determined the bioavailability of vitamin $\mathrm{E}$ from self-assembly structures in patients with diagnosed chronic pancreas insufficiency. Vitamin E solubilized in dispersed inverted bicontinuous cubic phase and in micellar formulation was delivered directly to the small intestine by tube-feeding. A cross-over study with randomization of 6 subjects and 2 treatments including a combined dose of $18 \mathrm{mg}(27 \mathrm{IU})$ of vitamin $\mathrm{E}\left(R R R-\left[5,7-\right.\right.$ methyl- $\left.\left.^{2} \mathrm{H}_{6}\right)\right]-$ $\alpha$-tocopherol) and $27 \mathrm{mg}(27 \mathrm{IU})$ vitamin $\mathrm{E}$ acetate $\left(R R R\right.$-[5-methyl- $\left.{ }^{2} \mathrm{H}_{3}\right]-\alpha$-tocopheryl acetate) was applied over a time period of $1 \mathrm{~h}$. Plasma samples were collected for $56 \mathrm{~h}$ and analyzed by liquid chromatography-mass spectrometry. Appearance of labeled tocopherols originating from the treatment started at $25 \mathrm{~h}$ and reached $\mathrm{C}_{\max }\left(0.6-4.6 \mu \mathrm{M}\right.$ depending on subject) in the 7-9 h window. From the $\mathrm{T}_{\max }$ onwards, both forms of tocopherols diminished slowly to $30-50 \%$ of their maxima within $56 \mathrm{~h}$. Strong inter-individual variation was observed in the plasma appearance curves (relative standard deviation varied between 38-45\%). No significant discrimination was found between the absorption of free or acetylated forms of deuterated $\alpha$-tocopherol confirming that application of acetylated $\alpha$-tocopherol provides the same bioavailability as free $\alpha$-tocopherol. This observation is valid in both dispersed inverted bicontinuous cubic phase and micellar formulations. Furthermore, since the area-underthe-curve values from cubic phase and from micellar formulations are similar, the cubic phase formulation could represent an alternative delivery system for lipophilic micronutrients in conditions or studies where polysorbatebased micelles cannot be generated.
\end{abstract}

Keywords: Bioavailability $\cdot$ Chronic pancreas insufficiency $\cdot$ Self-assembly systems $\cdot$ Vitamin E

\section{Introduction}

Vitamin E (tocopherols and tocotrienols) is the major and most potent lipid-soluble antioxidant in vivo. ${ }^{[1-3]}$ It acts as radical scavenging antioxidant in lipoproteins and efficiently interrupts the

\footnotetext{
${ }^{*}$ Correspondence: Prof. M. Kussmann ${ }^{\text {efg }}$ Tel.: +41216326106

E-mail: martin.kussmann@rd.nestle.com ${ }^{a}$ Nestlé Research Center, Nestec Ltd., Lausanne, Switzerland

${ }^{b}$ Digestive System Research Unit, Institut de Recerca Vall d'Hebron; Department of Gastroenterology, Hospital Universitari Vall d'Hebron, Universitat Autònoma de Barcelona (Department of Medicine), Barcelona, Spain

'Digestive Diseases Unit, Hospital de Sabadell, Institut Universitari Parc Taulí, Universitat Autònoma de Barcelona, Sabadell, Spain.

${ }^{\circledR}$ Centro de Investigación Biomédica en Red de Enfermedades Hepáticas y Digestivas (CIBERehd), Instituto de Salud Carlos III, Madrid, Spain

eMolecular Biomarkers Core, Nestlé Institute of Health Sciences, Campus EPFL, Quartier de l'innovation, bâtiment $\mathrm{H}, \mathrm{CH}-1015$ Lausanne, Switzerland

${ }^{\mathrm{f} E}$ cole Polytechnique Fédérale Lausanne (EPFL), Lausanne, Switzerland

9Faculty of Science, Aarhus University, Aarhus, Denmark

${ }^{n}$ School of Food Science and Nutrition, University of Leeds, Leeds, UK
}

chain propagation of lipid oxidation, thus protecting low-density lipoproteins from oxidation. ${ }^{[4]}$ Vitamin $E$ is also associated with lowered risk of coronary heart disease and atherosclerosis, ${ }^{[5,6]}$ and ischemic heart disease in cross-cultural epidemiology. ${ }^{[7]}$ Especially in clinical nutrition, vitamin E is often supplemented in the form of vitamin $\mathrm{E}$ acetate including the racemic mixture of eight stereoisomers. ${ }^{[8]}$

Vitamin E absorption is most severely impaired in cases where bile acid and/or pancreatic enzyme secretion are insufficient, typically for example in patients with exocrine pancreatic insufficiency (EPI). EPI is defined as inadequate pancreatic enzyme activity for digestion, caused by insufficient enzyme production, insufficient enzyme activation or disturbed enzyme deactivation. ${ }^{[9,10]}$ It often develops after surgery of the pancreas and stomach, ${ }^{[10]}$ and in many patients with chronic pancreatitis depending on the etiology of the disease. ${ }^{[11]}$ The symptoms of EPI are general maldigestion and malabsorption with weight loss, steatorrhoea and consequent vitamin deficiencies (especially of vitamins $\mathrm{A}, \mathrm{D}, \mathrm{E}$ and $\mathrm{K}){ }^{\left[{ }^{[10]}\right.}$ The abnormally low pancreatic secretion of bicarbonate in patients with EPI is associated with a limited buffering effect in the proximal intestine. Further, a pH below 4 is associated with an irreversible inactivation of endogenous and uncoated exogenous pancreatic lipase, as well as with precipitation of bile salts, contributing to fat maldigestion. ${ }^{[12]}$ The low circulating levels of micronutrients, fat-soluble vitamins and lipoproteins have been related to a high morbidity and mortality secondary to an increased risk of malnutrition-related complications and cardiovascular events. ${ }^{[13]}$ Overall, chronic pancreatitis is associated with a 4- to 5-fold increased risk of death compared to the general population matched by age and gender. ${ }^{[14,15]}$

A classic therapy for patients with EPI is to restrict fat intake in an attempt to reduce steatorrhoea: e.g. a diet containing less than $20 \mathrm{~g}$ fat daily is generally recommended in this context. Nevertheless, restriction of fat intake is linked to insufficient intake of fat-soluble vitamins, which are already malabsorbed in patients with pancreatic exocrine insufficiency.[16] Modern therapy of pancreatic exocrine insufficiency includes oral administration of exogenous pancreatic enzymes, ${ }^{[11]}$ however even using enteric-coated enzyme preparations in minimicrospheres, fat di- 
gestion does not revert to normal in almost half of the patients. ${ }^{[17]}$

Since vitamin $\mathrm{E}$ is a fat-soluble vitamin, its dispersion in aqueous environment is unstable. The rationale of using self-assembly systems is to ensure a homogenous and controlled dosage of the vitamin solution and possibly promote the diffusion of vitamins to the epithelium by mimicking the natural emulsification process of fats by bile salts. This latter is of particular importance, since patients with EPI often exhibit precipitation of bile salts due to the lower $\mathrm{pH}$ or no bile salt secretion during the experiment due to lack of bile stimulation. A possible risk of using selfassembly systems for the delivery of vita$\min \mathrm{E}$ is the unknown contribution of other components (emulsifiers) on the ultimate absorption process. This way, the studied absorption mechanism might be different from the real life system where no added emulsifiers are present. The objective of the current study was not to extrapolate to healthy conditions, but to evaluate the extent of vitamin $\mathrm{E}$ absorption with the above described self-assembly systems: cubosomes and micelles.

\section{Experimental}

\section{Subjects, Groups, Centers}

Male patients $(n=6)$ with diagnosed pancreas insufficiency were recruited locally at Vall d'Hebron Hospital, Barcelona. Inclusion criteria were $18-65 \mathrm{y}$, male, underwent successful pancreatectomy or was diagnosed with pancreas insufficiency minimum 1 year ago, fully recovered from pancreatectomy, as determined by physical and medical questionnaire, BMI 18-28 kg/ $\mathrm{m}^{2}$, serum vitamin E 6-21 mg/L, triglyceride $0.45-1.85 \mathrm{~g} / \mathrm{L}$, cholesterol 1.3-2.2 g/L and a ratio of $0.0045-0.006$ for vitamin E/ cholesterol. Levels of psychological stress: less than 300 points in the last year according to 'The social readjustment rating scale' ${ }^{[18]}$ and less than 25 points, in the last month, according to the "Global Measure of Perceived Stress'. [19]

Exclusion criteria were food or latex allergy or known allergy (casein) to any of the perfusion components, any acute disease in the last month, active bowel disorder, history of severe bowel disorder, small bowel intestinal resection other than that associated with pancreatectomy or appendicectomy, renal insufficiency, or regular consumption of multivitamin/ mineral supplements. Regular medication including acetylsalicylates, nonsteroidal anti-inflammatory drugs, $\beta_{2}$-agonists, acetaminophen, antacids, anticholinergics, codeine, or opioid derivatives were allowed for up to 3 days before the treatment whereas any other drug or supplement was prohibited in the 2 weeks before the study. Moderate alcohol or caffeine ingestion was allowed up to the last $72 \mathrm{~h}$ before the study. Further exclusion criteria included participating or having participated in another clinical trial over the last 3 months before subject enrollment, or participating in chemotherapy or radiotherapy. All exogenous formulations were suspended $24 \mathrm{~h}$ before and throughout the study.

Seven participants enrolled for the study, all of them signed informed consent forms prior to the experiment. Subject personal information was protected by code. Six participants have completed the study. Clinical Study Protocol and Ethical Application were presented to and approved by the Ethical Committee of the Medical Faculty, at Vall d'Hebron, Barcelona and by the Nestlé Research Center Medical Unit (study number 08.30. NRC).

\section{Formulation and Dosage of Vitamin $E$}

For all treatments, deuterated $\alpha$-tocopherol (d6- $\alpha$-tocopherol; $R R R$-[5,7methyl- $\left.\left({ }^{2} \mathrm{H}_{6}\right)\right]$ - $\alpha$-tocopherol) (98 atom\%) and deuterated $\alpha$-tocopheryl acetate $(\mathrm{d} 3-\alpha-$ tocopheryl acetate; $R R R$-[5-methyl- $\left.{ }^{2} \mathrm{H}_{3}\right]-$ $\alpha$-tocopheryl acetate) (98 atom\%) from Orphachem (Clermont-Ferrand, France) were used. The use of deuterium labels enabled differentiation between interventionderived and endogenous/dietary vitamin E. The products were analyzed and certified for human consumption. d6- $\alpha$-Tocopherol and $\mathrm{d} 3$ - $\alpha$-tocopheryl acetate were solubilized in two self-assembly systems: i) inverted bicontinuous cubic phase (referred to as 'cubic phase') and ii) micellar solution.

The base buffer consisted of $10.8 \mathrm{mM}$ $\mathrm{KCl}, 240 \mathrm{mM} \mathrm{NaCl}, 4 \mathrm{mM} \mathrm{Na} \mathrm{HPO}_{4}, 20$ $\mathrm{mM}$ glucose, $70 \mathrm{mM}$ mannitol and $500 \mathrm{mg}$ phenol red (non-absorbable volume marker) dissolved in normal distilled water and $\mathrm{pH}$ adjusted to 7.4 with $0.5 \mathrm{M} \mathrm{NaOH}(0.5$ N), see Table 1 .

The cubic phase solution ready to use directly for perfusion was prepared by mixing the base cubic phase solution (Table 1) with bottled mineral water $1: 1.8$ and ultimately with the base buffer (Table 1). The preparation of the base cubic phase solution commenced with mixing ascorbyl palmitate with melted Dimodan U/J. Then d6- $\alpha$-tocopherol and $\mathrm{d} 3$ - $\alpha$-tocopheryl acetate were added to this melted mixture to form the lipid mixture. Lysolecithin and $\mathrm{Na}$ caseinate were added into bottled water under magnetic agitation. The lipid mixture, preheated to $70{ }^{\circ} \mathrm{C}$, was then added to the Lysolecithin/ $\mathrm{Na}$ caseinate solution also preheated to $70{ }^{\circ} \mathrm{C}$. The pre-dispersing treatment was done with an ultratur$\operatorname{rax}$ (Polytron) $4 \mathrm{~min}$ at position 5/10 and then the emulsion was passed through the Rannie homogenizer in continuous mode for $5 \mathrm{~min}$ at 450 bar. The cubosome dispersion was then transferred into 100 ml Pyrex bottles under nitrogen to avoid oxidation during sterilization and storage. The cubosome dispersions were sterilized using a standard heat treatment of $30 \mathrm{~min}$ at $121{ }^{\circ} \mathrm{C}$ in an autoclave Systec V100 (Systec, Germany). In the second step, this base cubic phase solution was mixed with bottled mineral water in a proportion of $1: 1.8$, yielding an intermediate cubic phase solution. Finally, the intermediate cubic phase was mixed with the base buffer in a proportion of 1:1. Mixing was assisted by sonication and agitation. The resulting ready-to-use cubic phase solution was kept at $37^{\circ} \mathrm{C}$ until use $(\max 2 \mathrm{~h})$. The particles, present in the dispersion (after mixing with the buffer), had an inverted bicontinuous structure. The structure was assessed by small angle X-ray scattering as explained by Yaghmur et al. ${ }^{[20]}$ The final cubic phase solution was also checked by light scattering and optical microscopy which showed that no substantial (if any) particle aggregation occurs between the mixing procedure and the perfusion.

The ready-for-use micelle solution was produced by solubilizing Tween $20^{\circledR}$, d6- $\alpha$ tocopherol and d3- $\alpha$-tocopheryl acetate in a diluted buffer solution (Table 1). Briefly, $36.4 \mathrm{mg}$ d6- $\alpha$-tocopherol and $54.6 \mathrm{mg}$ d3- $\alpha$-tocopheryl acetate were mixed with $600 \mathrm{mg}$ Tween $20^{\circledR}$ in a $40{ }^{\circ} \mathrm{C}$ water bath. This mixture was filled up to $600 \mathrm{~mL}$ using diluted buffer in a glass bottle. The bottle was flushed with argon, wrapped into aluminum foil and heated to $80^{\circ} \mathrm{C}$ under gentle agitation on a heater plate. After reaching $80{ }^{\circ} \mathrm{C}$, the solution kept at this temperature and agitated for $30 \mathrm{~min}$. Finally, the mixture was cooled down in a water bath and was kept at $37{ }^{\circ} \mathrm{C}$ until use ( $\max 2 \mathrm{~h}$ ). The resulting solution (containing the Tween $20^{\circledR}$, vitamin and buffer) was transparent and showed no difference compared to the buffer only (without Tween/vitamin). No particles were evidenced by Differential Interference Contrast (DIC) microscopy and dynamic light scattering using a Zetasizer Nano ZS device (Malvern) revealed an average particle size of about 10 $\mathrm{nm}$. The same results were obtained when polysorbate and vitamin concentrations were increased fourfold. It was confirmed that these attributes, and therefore vitamin solubilization, remains constant for the 15 $\mathrm{h}$ tested. This stability time is much longer than the clinical trial requirement which was two hours.

Heating was necessary to obtain a completely transparent solution and therefore to solubilize completely tocopherol in the micelles. This may explain why, recently, Ziani et al. ${ }^{[21]}$ did not evidence solubiliza- 
Table 1. Composition of the intermediate working solutions and the final dispersion of cubic phase (with deuterated tocopherols) and micellar Tween 20 solution.

\begin{tabular}{|c|c|c|c|c|c|c|}
\hline & & $\begin{array}{l}\text { Base buf- } \\
\text { fer (without } \\
\text { tocopherols) }\end{array}$ & $\begin{array}{l}\text { Diluted buf- } \\
\text { fer (without } \\
\text { tocopherols) }\end{array}$ & $\begin{array}{l}\text { Base disper- } \\
\text { sion } 1 \text { of } \\
\text { Cubosomes } \\
\text { (tocopherols } \\
\text { incorporated } \\
\text { into Cubo- } \\
\text { somes) }\end{array}$ & $\begin{array}{l}\text { Ready-to-use } \\
\text { tube feeding } \\
\text { solution } 1 \\
\text { with Cubo- } \\
\text { somes }\end{array}$ & $\begin{array}{c}\text { Ready-to-use } \\
\text { tube feeding } \\
\text { solution } 2 \\
\text { with Tween } \\
20\end{array}$ \\
\hline Component & $\begin{array}{c}\text { Molecular } \\
\text { weight [Da] }\end{array}$ & $\begin{array}{c}\text { Absolute } \\
\text { amount in } \\
150 \mathrm{ml} \text { base } \\
\text { buffer [mg] }\end{array}$ & $\begin{array}{c}\text { Absolute } \\
\text { amount in } \\
150 \mathrm{ml} \text { base } \\
\text { buffer [mg] }\end{array}$ & $\begin{array}{l}\text { Absolute } \\
\text { amount in } \\
300 \mathrm{ml} \mathrm{[mg]}\end{array}$ & $\begin{array}{c}\text { Absolute } \\
\text { amount in } \\
300 \mathrm{ml}[\mathrm{mg}]\end{array}$ & $\begin{array}{c}\text { Absolute } \\
\text { amount in } \\
300 \mathrm{ml}[\mathrm{mg}]\end{array}$ \\
\hline Potassium chloride & 74 & 120.8 & 60.4 & - & 120.8 & 120.8 \\
\hline Sodium chloride & 58 & 2103.9 & 1052.0 & - & 2103.9 & 2103.9 \\
\hline Disodium hydrogen phosphate & 142 & 85.2 & 42.6 & - & 85.2 & 85.2 \\
\hline Glucose & 180 & 540.6 & 270.3 & - & 540.6 & 540.6 \\
\hline Mannitol & 182 & 1913.1 & 956.6 & - & 1913.1 & 1913.1 \\
\hline d6- $\alpha$-tocopherol & 436 & - & - & 51.0 & 18.2 & 18.2 \\
\hline d3- $\alpha$-tocopheryl acetate & 475 & - & - & 76.5 & 27.3 & 27.3 \\
\hline Dimodan U/J monoglyceride & mixture & - & - & 1932.0 & 690.0 & - \\
\hline Ascorbyl-palmitate & 414 & - & - & 51.0 & 18.2 & - \\
\hline Polyglycerol ester & mixture & - & - & 339.0 & 121.1 & - \\
\hline $\begin{array}{l}\text { Sunlecithin A-1 (Lysophosphati- } \\
\text { dylcholine) }\end{array}$ & mixture & - & - & 19.5 & 7.0 & - \\
\hline Sodium caseinate & mixture & - & - & 390.0 & 139.3 & - \\
\hline Tween 20 & mixture & - & - & - & - & 297.0 \\
\hline
\end{tabular}

tion of vitamin $\mathrm{E}$ acetate inside polysorbate micelles at room temperature (without heating). In addition, in the study of Ziani et al.,[21] the composition of the solution was very different and in particular pure water was used, with no buffer.

In both final solutions, the concentration of d6- $\alpha$-tocopherol and $\mathrm{d} 3$ $\alpha$-tocopheryl acetate was $90 \mathrm{IU} / \mathrm{l}$ each (60.7 mg/L d6- $\alpha$-tocopherol, $89.3 \mathrm{mg} / \mathrm{L}$ d3- $\alpha$-tocopheryl-acetate). Total absolute amount of 27 IU of each d6- $\alpha$-tocopherol and $\mathrm{d} 3-\alpha$-tocopheryl acetate $(=18.2 \mathrm{mg} \mathrm{d} 6$ $\alpha$-tocopherol $+26.7 \mathrm{mg} \mathrm{d} 3$ - $\alpha$-tocopheryl acetate) were administered per treatment (300 mL solution).

\section{Treatment of Subjects}

An in vivo human duodenal tube-feeding was applied to deliver the vitamin E into the small intestine. Oral feeding was not applied in order to avoid potential stomach contractions, palatability problems and to standardize the delivery rate of the formulation. After positioning the feeding tube and connections, $300 \mathrm{ml}$ ready-to-use solution was delivered into the small intestine of each subject over $1 \mathrm{~h}$ (equivalent to $18.2 \mathrm{mg} \mathrm{d} 6-\alpha$-tocopherol and $26.7 \mathrm{mg}$ of $\mathrm{d} 3$ - $\alpha$-tocopheryl acetate). A schematic of the crossover trial design is shown in Fig. 1.
A venous catheter was placed in the forearm after successful tube insertion into the small bowel. Blood samples were collected in EDTA (ethylene-diaminetetraacetic acid) tubes ( $10 \mathrm{~mL}$ fractions) at time $0 \mathrm{~h}$ (beginning of tube feeding), and at 1, 3, 5, 7, 9, 11, 24, 26, 28, 30, 32, 34, 48 and $56 \mathrm{~h}$. After collection, blood samples were centrifuged for $10 \mathrm{~min}$ at $3000 \mathrm{~g}$ at
$4{ }^{\circ} \mathrm{C}$ to extract the plasma, which was kept at $-80{ }^{\circ} \mathrm{C}$.

\section{Randomization and Blinding Technique}

The classical 2-treatment 2-period crossover design was used, assigning half of the subjects with the sequence cubic phase $\rightarrow$ Tween $20^{\circledR}$ and half of the sub-

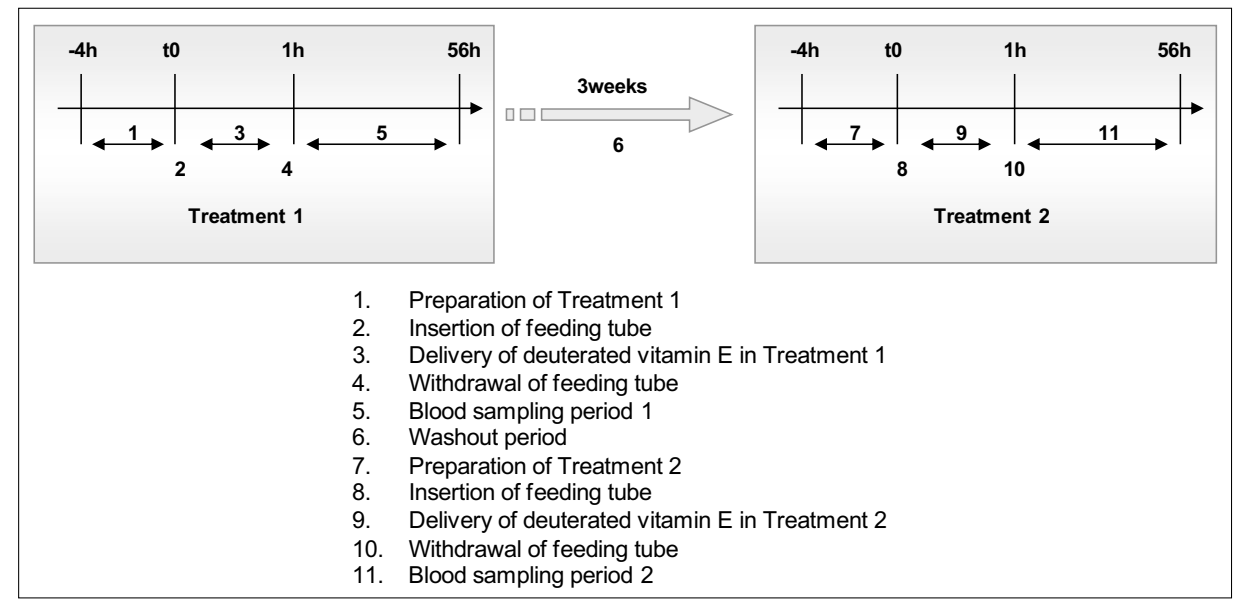

Fig. 1. Schematic representation of the crossover trial. The numbers correspond to the following events: 1: preparation of treatment 1; 2 : insertion of feeding tube; 3 : delivery of deuterated tocopherol in treatment $1 ; 4$ : withdrawal of feeding tube; 5 : blood sampling period $1 ; 6$ : washout period; 7: preparation of treatment 2; 8: insertion of feeding tube; 9: delivery of deuterated vitamin $\mathrm{E}$ in treatment 2; 10: withdrawal of feeding tube; 11: blood sampling period 2. 
jects with the sequence Tween $20^{\circledR} \rightarrow \mathrm{cu}$ bic phase. Application of the two tested products was double-blinded (treatments $\mathrm{A}$ and $\mathrm{B})$.

\section{Ingredients of the Self-assembly Systems}

Dimodan U/J (unsaturated monoglyceride), PGE 0 80/D (polyglycerol ester) and ascorbyl palmitate were from Danisco (Copenhagen, Denmark). Sunlecithin A1 (lysolecithin) was from Tayio Kagaku (Yokkaichi, Japan). Na-caseinate was from Emi (Luzern, Switzerland). Tween $20^{\circledR}$ was from Merck KgaA, Darmstadt, Germany.

\section{Chemicals}

HPLC grade water, ethanol, 1,4-dioxane, $n$-hexane, BHT (2,6-di-tert-butyl4-methylphenol) were obtained from VWR International AG, Dietikon, Switzerland. All-rac ${ }^{2} \mathrm{H}_{9}$ - $\alpha$-tocopherylacetate (2-methyl-5, 7,8-tri(methyl- $\left.{ }^{2} \mathrm{H}_{3}\right)-2-\left(4^{\prime}, 8^{\prime}, 12^{\prime}-\right.$ trimethyltridecyl)-6-chromanol-acetate was obtained from Sigma-Aldrich Chemie $\mathrm{GmbH}$, Buchs, Switzerland. All-rac ${ }^{2} \mathrm{H}_{0}-$ $\alpha$-tocopherol (2-methyl-5,7,8-tri(methyl$\left.{ }^{2} \mathrm{H}_{3}\right)$-2-(4',8',12'-trimethyltridecyl)-6-chromanol) was obtained from Chemaphor Inc., Ottawa, Canada.

\section{Sample Analysis}

Sample preparation, liquid chromatography and mass spectrometric analysis of the samples were performed as reported elsewhere. ${ }^{[22]}$ The $\mathrm{d} 9$ - $\alpha$-tocopherol and its acetate were used exclusively as internal standards for the LC-MS/MS analysis.

\section{Statistical Evaluation}

AUC of d6- $\alpha$-tocopherol and $\mathrm{d} 3-\alpha-$ tocopheryl acetate in blood were calculated according to the trapezoidal rule. Taking into account the distribution, Wilcoxon signed rank tests were performed. Statistical analyses were done with Statistical Analysis Systems software (version 9.1; SAS Institute, Cary, NC, USA).

\section{Results and Discussion}

\section{Plasma Appearance of Tube-fed Vitamin E}

Following the direct delivery of d6- $\alpha$ tocopherol and $\mathrm{d} 3$ - $\alpha$-tocopheryl acetate into the small intestine, it was possible to observe the appearance of both d6- and d3$\alpha$-tocopherol in the plasma. As an example, results from one subject are shown in Fig. 2. Note that during uptake, the d $3-\alpha-$ tocopheryl acetate is cleaved into free d3$\alpha$-tocopherol, meaning that in the plasma only the free $\mathrm{d} 3-\alpha$-tocopherol form appears and not the administered $\mathrm{d} 3$ - $\alpha$-tocopheryl acetate. Appearance of labeled tocopher- ols originating from the treatment started at $2-5 \mathrm{~h}$ and reached the $\mathrm{C}_{\max }$ value in the 7-9 $\mathrm{h}$ window. From $\mathrm{T}_{\max }$ onwards, both forms of tocopherols diminished slowly to $30-50 \%$ of their maximum within $56 \mathrm{~h}$. This suggests an elimination half-time of around 2 days, which is in accordance with the literature. ${ }^{[23-26]}$ Absolute levels of $\mathrm{d} 3$ and $\mathrm{d} 6$ - $\alpha$-tocopherol from this single dose were 10-20 times lower than the endogenous, non-labeled form. The latter parameter appeared to be stable for all subjects for the duration of the study - despite the restriction in the diet. Although the individuals exhibited major inter-individual variation in their plasma appearance curves (see Table 2 and Table 3), we attempted to correlate the observed absorption with data found in the literature. ${ }^{[23,25,26]}$ Taking $\mathrm{C}_{\text {max }}$ as the basis for comparison and converting the reported values corresponding to the dose of $27 \mathrm{mg}$ deuterated $\alpha$-tocopheryl acetate (assuming proportional relationship between dose and $\mathrm{C}_{\max }$ ), two publications report $\mathrm{C}_{\max }$ values of $1.8 \mu \mathrm{M}^{[26]}$ and $1 \mu \mathrm{M}^{[25]}$ when the deuterated $\alpha$-tocopheryl acetate is taken with a standard breakfast (containing 30-40 g fat), while a third study reports a $\mathrm{C}_{\max }$ value of $3.6 \mu \mathrm{M}^{\text {[23] }}$ when deuterated $\alpha$-tocopheryl acetate is ingested with cereals. Bruno et al. report linear correlation between $\mathrm{C}_{\max }$ of plasma tocopherol as a function of breakfast fat content returning $2.2 \mu \mathrm{M}$ and $4.2 \mu \mathrm{M}$ when deuterated $\alpha$-tocopheryl acetate was taken in the form of fortified apple without or with $6 \%$ fat respectively. ${ }^{[27]}$ According to these approximations, the absorption of deuterated $\alpha$-tocopheryl acetate from the cubic phase described herein (average $\mathrm{C}_{\max }$ for all subjects is $3 \mu \mathrm{M}$ ) is higher than from supplements taken with a standard breakfast or fortified apple, but lower than from fortified cereals or from fortified apple that contained $6 \%$ fat. One reason for the high absorption from fortified cereals could be that the cereals slow down the transit of ingested food in the gut hereby extending the time available for the absorption. Overall, the delivery power appears better than under conditions of a standard breakfast suggesting that the cubic phase could serve as a good basis to achieve improved vitamin E bioavailability i) under malabsorbing conditions; ii) in patients where the solid food intake (e.g. cereals) is not an option; and iii) in low-fat diets.

Cheeseman et al. ${ }^{[28]}$ reported similar absorption kinetics of free and acetylated $\alpha$-tocopherols in healthy subjects, meaning in the presence of pancreas and bile salts. In our study, the absorption of free and acetylated tocopherols was compared under pancreas insufficiency conditions. After standardization to the original product composition and statistical evaluation, no significant discrimination was evident between the absorption of free or acetylated form of $\alpha$-tocopherol as judged by the AUC of $\mathrm{d} 3$ - and $\mathrm{d} 6$ - $\alpha$-tocopherol (Table 4). The results indicate that the more stable $\alpha$-tocopheryl acetate with longer shelf life is just as efficiently absorbed as the free tocopherol even in cases of pancreas insufficiency.

\section{Comparison of Absorption from Cubic Phase and from Micellar Solution}

AUCs of d3- and d6- $\alpha$-tocopherol appearing in the plasma from the cubic phase and micellar solution were compared. The subjects underwent treatment with both products in a cross-over manner, (Fig. 1). As an example, Fig. 3 depicts the AUCs of the three types of tocopherols in the case of

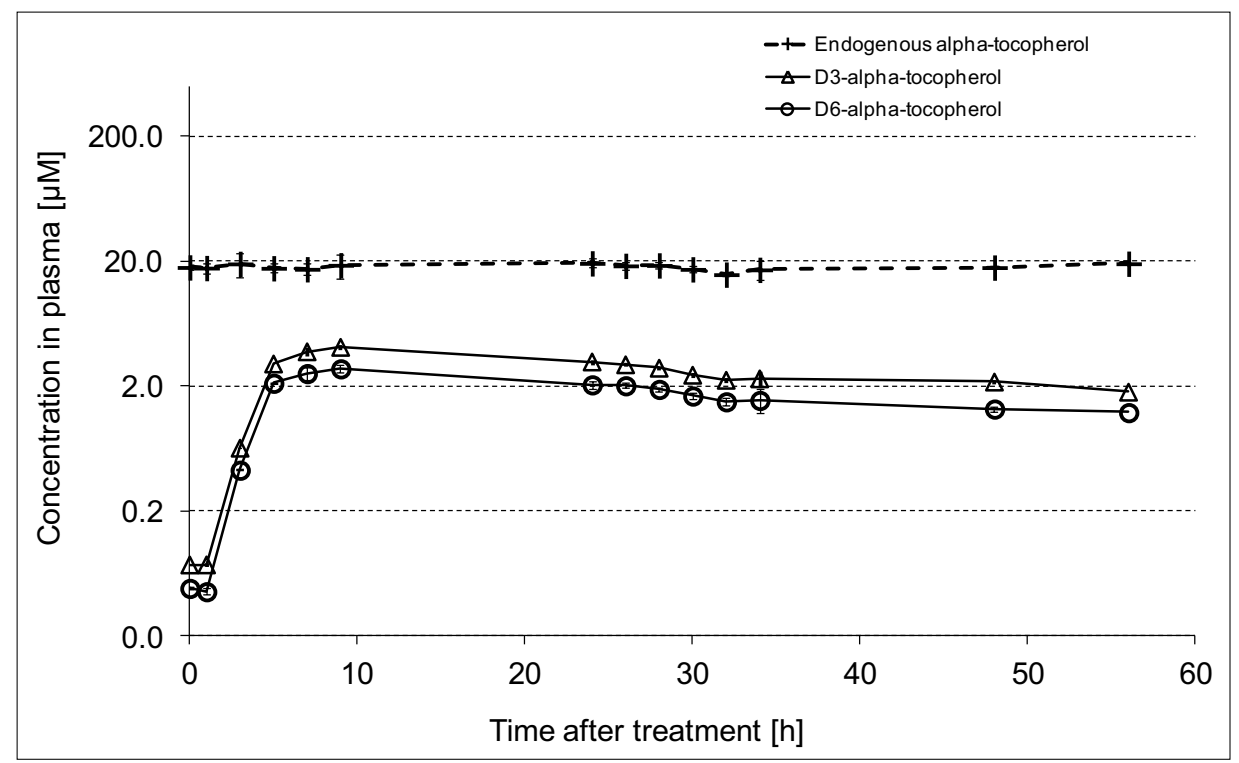

Fig. 2. Appearance of deuterated $\alpha$-tocopherols in the plasma as a consequence of tube feeding: d3- $\alpha$-tocopherol $(\triangle)$, d6- $\alpha$-tocopherol $(\bigcirc)$,endogenous $\alpha$-tocopherol $(+)$. 
Table 2. AUC values of deuterated tocopherols in patients. Note: The AUC for micelles was not calculated for subject 5 , because of lack of sampling points between 5 and $24 \mathrm{~h}$.

\begin{tabular}{|c|c|c|c|c|c|c|}
\hline Subject & Treatment & Analyte & $\mathrm{T}_{\max }$ & $\begin{array}{l}\mathrm{C}_{\max } \\
{[\mu \mathrm{M}]}\end{array}$ & $\mathrm{t}_{1 / 2}[\mathrm{~h}]$ & $\begin{array}{c}\text { AUC baseline } \\
\text { corrected }\left[\mu \mathrm{M}^{*} \mathrm{~h}\right]\end{array}$ \\
\hline \multirow[t]{4}{*}{1} & \multirow{2}{*}{ Micelles } & d3- $\alpha$-tocopherol & 24 & 2.18 & 48.5 & 77.9 \\
\hline & & d6- $\alpha$-tocopherol & 24 & 1.16 & 48.2 & 41.0 \\
\hline & \multirow{2}{*}{ Cubosomes } & d3- $\alpha$-tocopherol & 24 & 2.55 & 52.2 & 100.7 \\
\hline & & d6- $\alpha$-tocopherol & 24 & 1.71 & 50.8 & 66.7 \\
\hline \multirow[t]{4}{*}{2} & \multirow{2}{*}{ Micelles } & d3- $\alpha$-tocopherol & 7 & 1.57 & 45.1 & 54.7 \\
\hline & & d6- $\alpha$-tocopherol & 7 & 1.10 & 48.1 & 39.6 \\
\hline & \multirow{2}{*}{ Cubosomes } & d3- $\alpha$-tocopherol & 26 & 2.14 & $>56$ & 77.7 \\
\hline & & d6- $\alpha$-tocopherol & 26 & 1.46 & $>56$ & 54.8 \\
\hline \multirow[t]{4}{*}{3} & \multirow{2}{*}{ Micelles } & d3- $\alpha$-tocopherol & 7 & 4.56 & 41.9 & 143.9 \\
\hline & & d6- $\alpha$-tocopherol & 7 & 2.66 & 41.4 & 84.4 \\
\hline & \multirow{2}{*}{ Cubosomes } & d3- $\alpha$-tocopherol & 9 & 4.14 & 44.9 & 141.0 \\
\hline & & d6- $\alpha$-tocopherol & 9 & 2.75 & 43.9 & 94.0 \\
\hline \multirow[t]{4}{*}{4} & \multirow{2}{*}{ Micelles } & d3- $\alpha$-tocopherol & 7 & 1.80 & $>56$ & 75.5 \\
\hline & & d6- $\alpha$-tocopherol & 7 & 1.10 & $>56$ & 46.6 \\
\hline & \multirow{2}{*}{ Cubosomes } & d3- $\alpha$-tocopherol & 3 & 0.83 & 54.4 & 33.1 \\
\hline & & d6- $\alpha$-tocopherol & 7 & 0.62 & 50.3 & 25.8 \\
\hline \multirow[t]{4}{*}{5} & \multirow{2}{*}{ Micelles } & d3- $\alpha$-tocopherol & - & - & $>56$ & - \\
\hline & & d6- $\alpha$-tocopherol & - & - & $>56$ & - \\
\hline & \multirow{2}{*}{ Cubosomes } & d3- $\alpha$-tocopherol & 9 & 4.06 & 46.7 & 148.9 \\
\hline & & d6- $\alpha$-tocopherol & 9 & 2.68 & $>56$ & 105.5 \\
\hline \multirow[t]{4}{*}{6} & \multirow{2}{*}{ Micelles } & d3- $\alpha$-tocopherol & 9 & 3.44 & 38.3 & 111.6 \\
\hline & & d6- $\alpha$-tocopherol & 8 & 2.56 & 36.8 & 82.2 \\
\hline & \multirow{2}{*}{ Cubosomes } & d3- $\alpha$-tocopherol & 9 & 4.53 & 45.4 & 160.5 \\
\hline & & d6- $\alpha$-tocopherol & 7 & 2.97 & 47.8 & 108.0 \\
\hline
\end{tabular}

Table 3. Area under the curve (AUC) for perfusion experiments.

\begin{tabular}{|c|c|c|c|c|c|c|}
\hline & & $\begin{array}{c}\text { Mean } \\
{\left[\mu \mathrm{M}^{*} \mathrm{~h}\right]}\end{array}$ & $\begin{array}{l}\text { relative } \\
\mathrm{SD}[\%]\end{array}$ & $\begin{array}{l}\text { Median } \\
{[\mu \mathrm{M} * \mathrm{~h}]}\end{array}$ & $\begin{array}{c}\text { Mini- } \\
\text { mum } \\
{\left[\mu \mathrm{M}^{*} \mathrm{~h}\right]}\end{array}$ & $\begin{array}{c}\text { Maxi- } \\
\text { mum } \\
{\left[\mu \mathrm{M}^{*} \mathrm{~h}\right]}\end{array}$ \\
\hline \multirow{2}{*}{$\begin{array}{l}\text { Micelles } \\
(\mathrm{N}=5)\end{array}$} & d3- $\alpha$-tocopherol & 92.7 & 37.9 & 77.9 & 54.7 & 143.9 \\
\hline & d6- $\alpha$-tocopherol & 58.8 & 38.4 & 46.6 & 39.1 & 84.4 \\
\hline \multirow{2}{*}{$\begin{array}{l}\text { Cubosomes } \\
(\mathrm{N}=6)\end{array}$} & d3- $\alpha$-tocopherol & 110.3 & 44.5 & 120.9 & 33.1 & 160.5 \\
\hline & d6- $\alpha$-tocophero/ & 75.8 & 42.8 & 80.4 & 25.8 & 108.0 \\
\hline
\end{tabular}

Table 4. Significance in the AUC values obtained for free and acetylated $\alpha$-tocopherols and of different formulations after tube feeding.

\begin{tabular}{|l|l|c|c|c|}
\hline & & $\begin{array}{c}\text { Lower } \\
95 \% \text { CI }\end{array}$ & $\begin{array}{c}\text { Upper } \\
95 \% \text { CI }\end{array}$ & $p$-value \\
\hline Micelles & d3- versus d6- $\alpha$-tocopherols & -13.19 & 1.906 & 0.125 \\
\hline Cubosomes & d3- versus d6- $\alpha$-tocopherols & -8.554 & 1.605 & 0.063 \\
\hline & & Lower & Upper & \\
\hline d3- $\alpha$-tocopherols & Cubosomes versus Micelles & -9.25 & 30.82 & 0.625 \\
\hline d6- $\alpha$-tocopherols & Cubosomes versus Micelles & -0.59 & 20.78 & 0.313 \\
\hline
\end{tabular}

the two treatments (micelles=treatment $\mathrm{A}$, cubic phase $=$ treatment B). Fig. $3 \mathrm{~A}$ and $3 \mathrm{~B}$ depict AUCs of d3- and d6- $\alpha$-tocopherol, respectively. Fig. 3C shows the AUCs of endogenous, non-labeled $\alpha$-tocopherol in the case of both treatments. After statistical evaluation of the data from all subjects, the absorption of tocopherols overall was similar using both delivery systems, see Table 4. These results suggest that the cubic phase represents an alternative to micelles for delivery of vitamin $\mathrm{E}$ and potentially other fat-soluble vitamins.

\section{Conclusions}

Bioavailability of tocopherols was investigated under pancreas insufficiency conditions. The results show that the free and acetylated forms of $\alpha$-tocopherol are absorbed equally well independent of the applied self-assembly system structure, e.g. cubic-phase or micellar formulations. Accordingly, these results suggest that the more stable, acetylated form of tocopherol with longer shelf life can be used to deliver vitamin $\mathrm{E}$ under these pathophysiological conditions. Furthermore, since the AUCs from cubic-phase and micellar formulations are similar, the cubic-phase formulation could represent an alternative delivery system for lipophilic micronutrients in studies where polysorbate-based micelles cannot be generated.

\section{Acknowledgements}

The authors would like to thank Rosemarie Jenni, Corinne Appolonia-Nouzille, Veronique Clement and Drs. Laurent Fay, Michael Affolter, Corinne Magliola, Serge Rezzi and Martin Leser for the constructive consultations and for their valuable help. We also would like to thank Milagros Gallart, Monserrat Casellas, Purificación Rodríguez for their help in preparing perfusion buffers and assisting on experimental procedures.

Contributions: The authors' responsibilities were as follows K.N., F.A., M. J-R., M.B., J.M., M.K., J.S., B.H., G.W.: study concept and design; K.N., L.R., M-C. C-C., S. B-L., B.L., M.B., S.A., L.S., J.S.: conduct of experiments K.N., M-C. C-C., S. B-L., B.L.: acquisition of data; K.N., J.M., J.S., G.W.: analysis and interpretation of data; K.N., J.S., G.W.: drafting of the manuscript; M.B., L.S., J.M., M.K., J.S., G.W.: revision of the manuscript; J.M.: statistical analysis; F.A., M. J-R. M.: study supervision and funding.

Received: January 28, 2014

[1] G. W. Burton, A. Joyce, K. U. Ingold, Arch. Biochem. Biophys. 1983, 221, 281.

[2] K. U. Ingold, A. C. Webb, D. Witter, G. W Burton, T. A. Metcalfe, D. P. Muller, Arch. Biochem. Biophys. 1987, 259, 224.

[3] P. P. Hoppe, G. Krennrich, Eur. J. Nutr. 2000, 39, 183.

[4] P. A. Morrissey, P. J. Sheehy, Proc. Nutr. Soc. 1999, 58, 459. 


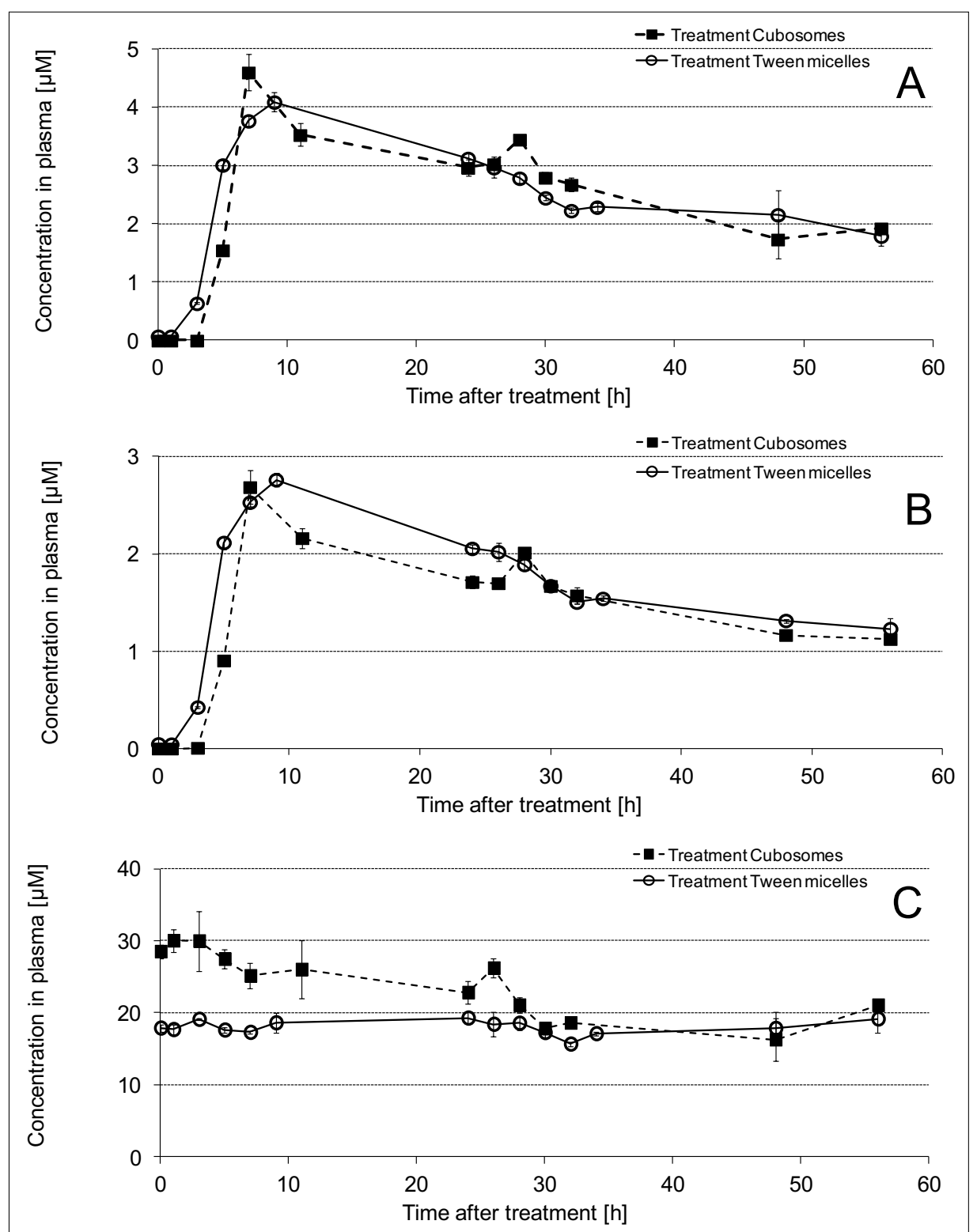

Fig. 3. Comparison of plasma appearance of various tocopherols in the same subject. The full squares represent the cubic phase-based interventions, while the empty circles represent the micelle-based interventions. Window A depicts the appearance of $\mathrm{d} 3-\alpha$-tocopherol, window B shows the appearance of $d 6$ - $\alpha$-tocopherol, while window $C$ shows the level of endogenous $\alpha$-tocopherol.
[5] P. M. Bramley, I. Elmadfa, A. Kafatos, F. J. Kelly, Y. Manios, H. E. Roxborough, W. Schuch. P. J. A. Cheehy, K.-H. Wagner, J. Sci. Food Agri. 2000, 80, 913.

[6] M. G. Traber, H. Sies, Anпи. Rev. Nutr. 1996, 16,321 .

[7] K. F. Gey, P. Puska, P. Jordan, U. K. Moser, Amer. J. Clin. Nutr. 1991, 53, 326S.

[8] J. E. Maras, O. I. Bermudez, N. Qiao, P. J. Bakun, E. L. Boody-Alter, K. L. Tucker, J. Amer. Diet. Assoc. 2004, 104, 567.

[9] J. E. Dominguez-Munoz, Curr. Gastroenterol. Rep. 2007, 9, 116.

[10] H. Friess, C. W. Michalski, HPB (Oxford) 2009, $11,7$.

[11] J. E. Dominguez-Munoz, J. Gastroenterol. Hepatol. 2011, 26, 12.

[12] E. P. DiMagno, J. R. Malagelada, V. L. Go, C. G. Moertel, N. Engl. J. Med. 1977, 296, 1318.

[13] G. Montalto, M. Soresi, A. Carroccio, E. Scafidi, C. M. Barbagallo, S. Ippolito, A. Notarbartolo, Pancreas 1994, 9, 137.

[14] P. G. Lankisch, Pancreatology 2001, 1, 3.

[15] C. Nojgaard, F. Bendtsen, U. Becker, J. R. Andersen, C. Holst, P. Matzen, Clin. Gastroenterol. Hepatol. 2010, 8, 384.

[16] J. E. Dominguez-Munoz, J. Iglesias-Garcia, M. Vilarino-Insua, M. Iglesias-Rey, Clin. Gastroenterol. Hepatol. 2007, 5, 484.

[17] J. E. Dominguez-Munoz, J. Iglesias-Garcia, M. Iglesias-Rey, M. Vilarino-Insua, Gut 2006, 55, 1056.

[18] T. H. Holmes, R. H. Rahe, J. Psychosom. Res. 1967, 11, 213.

[19] S. Cohen, T. Kamarck, R. Mermelstein, J. Health Soc. Behav. 1983, 24, 385.

[20] A. Yaghmur, L. deCampo, L. Sagalowicz, M. E. Leser, O. Glatter, Langmuir 2006, 22, 9919.

[21] K. Ziani, Y. Fang, D. J. McClements, Food Chem. 2012, 134, 1106.

[22] K. Nagy, M. C. Courtet-Compondu, B. Holst, M. Kussmann, Anal. Chem. 2007, 79, 7087.

[23] S. W. Leonard, C. K. Good, E. T. Gugger, M. G. Traber, Amer. J. Clin. Nutr. 2004, 79, 86.

[24] M. G. Traber , R. Ramakrishnan, H. J. Kayden, Proc. Natl. Acad. Sci. USA 1994, 91, 10005.

[25] M. G. Traber, D. Rader, R. V. Acuff, R. Ramakrishnan, H. B. Brewer, H. J. Kayden, Amer. J. Clin. Nutr. 1998, 68, 847.

[26] A. R. Proteggente, R. Turner, J. Majewicz, G. Rimbach, A. M. Minihane, K. Kramer, J. K. Lodge, J. Nutr. 2005, 135, 1063.

[27] R. S. Bruno, S. W. Leonard, S. Park, Y. Zhao, M. G. Traber, Am. J. Clin. Nutr. 2006, 83, 299.

[28] K. H. Cheeseman, A. E. Holley, F. J. Kelly, M. Wasil, L. Hughes, G. Burton, Free Radic. Biol. Med. 1995, 19, 591. 